\title{
A Printed LPDA Antenna Fed by a Microstrip Line to Double Sided Parallel Strip Line from Backside
}

\author{
Zhou Yang, Huang Jingjian, Wu Weiwei, and Yuan Naichang \\ College of Electronic Science and Engineering, National University of Defense Technology, Changsha, Hunan, China \\ Correspondence should be addressed to Zhou Yang; zhouyangantelope@163.com
}

Received 3 May 2017; Revised 18 August 2017; Accepted 29 August 2017; Published 8 October 2017

Academic Editor: Giorgio Montisci

Copyright (c) 2017 Zhou Yang et al. This is an open access article distributed under the Creative Commons Attribution License, which permits unrestricted use, distribution, and reproduction in any medium, provided the original work is properly cited.

\begin{abstract}
A novel planar printed log-periodic dipole array (LPDA) antenna fed by tapered microstrip line (MSL) to double sided parallel strip line (DSPSL) is proposed in this paper. The proposed antenna adopts MSL feeding approach from backside. Using this feeding technique makes the printed LPDA antenna easier to be integrated into radio frequency (RF) circuits. In this paper, four layers are used to construct the antenna. The four layers of the printed LPDA antenna are printed on three thin dielectric substrates which are integrated together. To validate this approach, a printed LPDA antenna is simulated and fabricated for operating in the S and C bands $(2.5-6 \mathrm{GHz})$. The antenna showed a good result over the whole frequency range with $2: 1 \mathrm{VSWR}$, an average gain of $6.5 \mathrm{~dB}$, and stable radiation patterns. The measured results are in very good agreement with simulations.
\end{abstract}

\section{Introduction}

With the development of RF integrated circuits and systems, antennas have received more and more attention for their bulky and outstanding properties in the communication systems. Moreover, there are more than one antenna in a system in most cases. In order to reduce the complexity of the system, a broadband antenna that can be applied to multiple frequency bands is necessary. For the demand of ultrawide bandwidth, low profile, light-weight, and easyto-manufacture and integration, the printed LPDA antenna [1] is a good candidate to comply with all these requirements. The printed LPDA antenna also can be designed following the suggestion given by Carrel [2]. Feeding techniques are the crucial point in designing LPDA antennas especially in designing the printed LPDA antennas. Since a printed LPDA antenna is a balanced structure, a balun is often used between the transmission line and the antenna. The DSPSL has been used for many transitions [3] and antennas [4] for its balanced transmission and wideband transitions. Due to the end-fire radiation characteristics of the LPDA antenna, most of the printed LPDA antennas are fed by a DSPSL from head of the antenna. Therefore, an extra transmission line must be used in the feeding technique.
Usually a coaxial cable is used to excite the LPDA antennas $[5,6]$. This feeding technique presents some drawbacks such as the difficulty of soldering process and can deteriorate both the radiation pattern and the antenna matching. To overcome the shortcomings of this feeding technique, an ultrawideband planar LPDA antenna with mode converter balun is designed in [7] and an antenna is designed by introducing a subsectional tapered feed line instead of standard MSL feeding in [8]. However, these feeding techniques feed from head of the antenna. Undoubtedly, they increase the integration difficulties between the printed LPDA antenna and RF circuits. Thus, to seek a planar feeding technique from backside is necessary. A microwave printed planar LPDA antenna analysis and design procedure is presented together with the description of a planar feeding technique in $[9,10]$. These feeding techniques use a strip line. It is also difficult to be integrated with the printed circuit. Also, a printed LPDA antenna fed by a coplanar waveguide (CPW) is presented in [11, 12]. However, these antennas are also somewhat complicated in terms of integration with other RF circuits. In [13], a non-cross-feeding structure is adopted to avoid the feeing technique with coaxial line. But feeding on long dipole in this antenna leads to the decline of efficiency and the limitation of bandwidth. 
TABLE 1: Dimensions of the dipoles in printed LPDA antenna.

\begin{tabular}{lccc}
\hline Dipole & $l_{n}(\mathrm{~mm})$ & $d_{n}(\mathrm{~mm})$ & $w_{n}(\mathrm{~mm})$ \\
\hline 1 & 46.50 & 10.60 & 3.00 \\
2 & 40.20 & 9.12 & 2.58 \\
3 & 34.78 & 7.84 & 2.22 \\
4 & 30.12 & 6.74 & 1.91 \\
5 & 26.12 & 5.80 & 1.64 \\
6 & 22.67 & 4.99 & 1.41 \\
7 & 19.71 & 4.29 & 1.21 \\
8 & 17.16 & 3.69 & 1.04 \\
9 & 14.96 & 3.17 & 0.90 \\
10 & 13.08 & & 0.77 \\
\hline
\end{tabular}

In this paper, a printed LPDA antenna fed by a MSL to DSPSL from backside is described. MSLs are the very familiar transmission lines which are often employed to feed the printed antennas. In order to realize the planar feeding technique, a tapered microstrip balun $[14,15]$, which is a transform of MSL to DSPSL, is used. A tapered microstrip balun is relatively easy to manufacture compared to the above feeding techniques and easy to connect with the external SMA connectors or other RF circuits. The drawback is that this antenna uses a four-layer circuit board instead of two-layer circuit board with respect to other antennas. The proposed antenna can satisfy many communication systems, such as WiMAX (3.3-3.6 GHz), C-band satellite communication systems $(3.7-4.2 \mathrm{GHz})$, and WLAN (5.15-5.825 GHz).

\section{Antenna Design and Configurations}

General configuration of LPDA antennas is described by the scaling factor $\tau=l_{n+1} / l_{n}=d_{n+1} / d_{n}=w_{n+1} / w_{n}$, where $d_{n}$ is the distance between the $n$th element and the $(n+1)$ th element and $l_{n}$ and $w_{n}$ are the length and width of the $n$th element, respectively. The spacing factor is $\sigma=d_{n} / 2 l_{n}$ [16]. In this paper, it is intended to design a printed LPDA antenna with VSWR $<2$ and a gain of $7 \mathrm{~dB}$ to cover the frequency range from $2.5 \mathrm{GHz}$ to $6 \mathrm{GHz}$. The basic parameters are $\tau=0.86$ and $\sigma=0.12$. The substrate includes three parts and every part of the substrate uses a Rogers RO4003 substrate with relative dielectric permittivity $\varepsilon_{r}=3.38$, thickness $s t=0.5 \mathrm{~mm}$, and loss tangent $\delta=0.0027$. Thus, the total thickness of the printed LPDA antenna is approximately $1.6 \mathrm{~mm}$. The lengths of the dipoles are related to the effective dielectric constant $\varepsilon_{e}$ of the substrate. At last, the final parameters are confirmed by the simulation software. The simulation is done employing the electromagnetic software CST Microwave Studio. The dipoles of the printed LPDA antenna, shown in Figure 1(a), are numbered $1,2, \ldots, N$. The total number of elements of $N$ is 10 to ensure bandwidth allowance. The tuned parameters of the dipoles are given in Table 1 . The antenna elements are printed on a four-layer substrate. The dipoles of the printed LPDA antenna are printed on the top layer and bottom layer. The configuration of the proposed antenna is shown in Figure 1(b).
The transmission lines are printed on the second layer and third layer. The second layer is connected to the $50 \Omega$ SMA connector. The third layer is connected to the ground of the SMA. The MSL to DSPSL tapered transition geometry consists of a ground plane, which is gradually converted into a strip. The characteristic impedance of the MSL is chosen to be equal to $50 \Omega$ for obtaining an easy matching with the standard SMA connector or other RF circuits. Thus the values of parameters $w t, w b$, and $h$ are gotten. DSPSL 1 is printed on the second layer and third layer. The characteristic impedance of the DSPSL 1 is chosen to be $50 \Omega$ to match with the MSL and the DSPSL 2.

The width of the transmission line DSPSL 2 on the top layer and bottom layer is the same width with DSPSL 1. The width of the DSPSL 1 and DSPSL 2 is $w k$. The value of the parameter $w k$ is $1.5 \mathrm{~mm}$, which is calculated from theory of transmission line. The MSL and DSPSL are shown in Figure 1(a). The parameter $k l$ has a great impact on the antenna matching. In addition to the parameter $k l$, the other parameters use the values in Tables 1 and 2 . To seek a suitable value of this parameter, the proposed antenna is simulated under different values of parameter $k l$. The results are shown in Figure 2. When the length of $k l$ is $6 \mathrm{~mm}$, the best impedance matching can be gotten. The tuned parameters of the transmission lines are given in Table 2. At last, the four layers are integrated together, shown in Figure 1(b), by using three separate substrates. The width and length of the substrate are also depicted in Table 2 . The Via 1 connects the top layer and the second layer at the head of the antenna. The Via 2 connects the third layer and the bottom layer at the head of the antenna in the same way. So this way provides a balun to excite the printed LPDA antenna. The Via 3 connects the top layer and bottom layer. A terminal resistor with $50 \Omega$ is connected to the open end of the printed LPDA antenna to absorb the residual power.

\section{Results and Discussion}

Usually the electromagnetic energy supplied by the signal source is transmitted from the vertex along the transmission line in the printed LPDA antenna. Only the elements with lengths close to the resonant length can radiate. We call these elements the active region. Figure 3 shows the distributions 


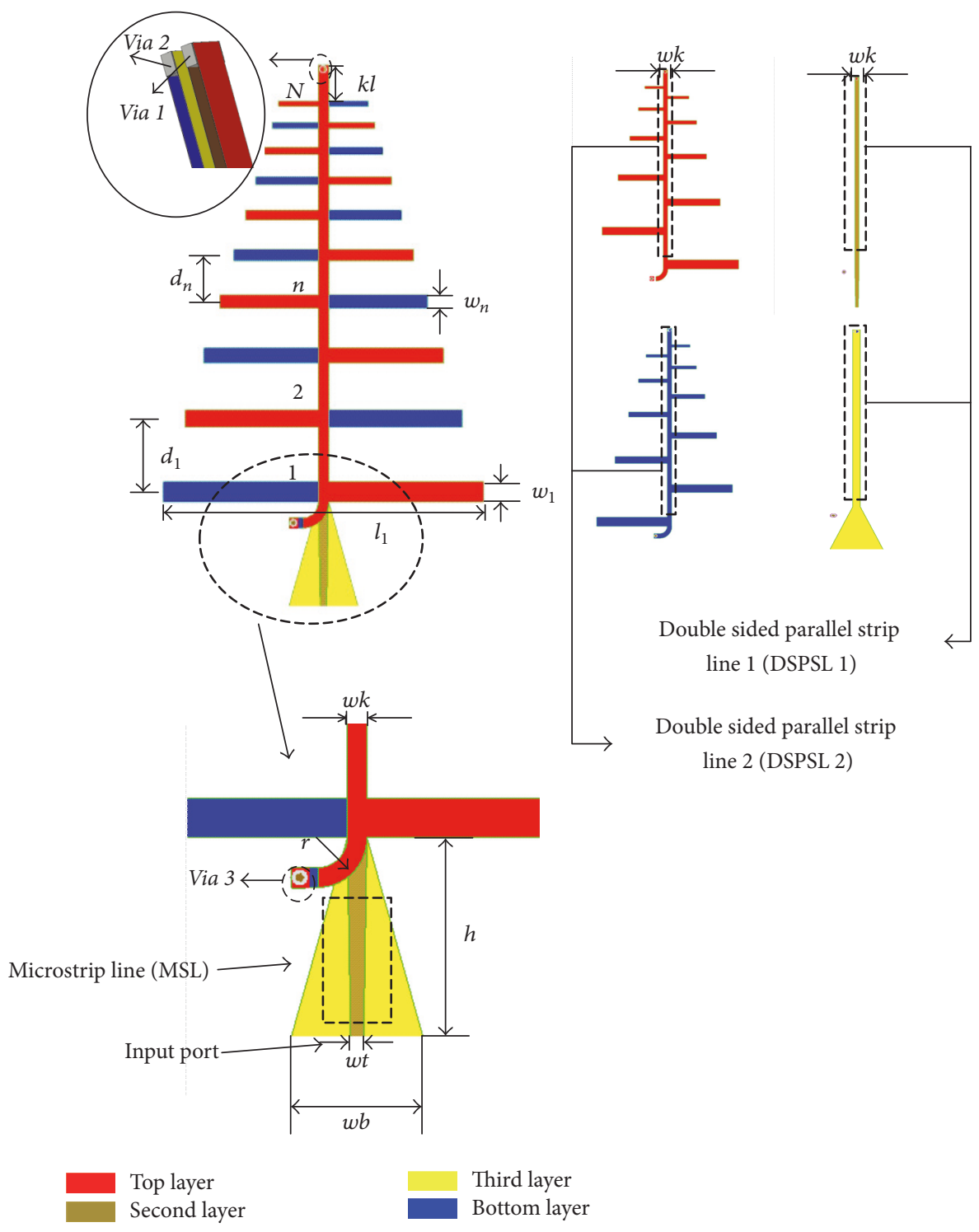

(a)

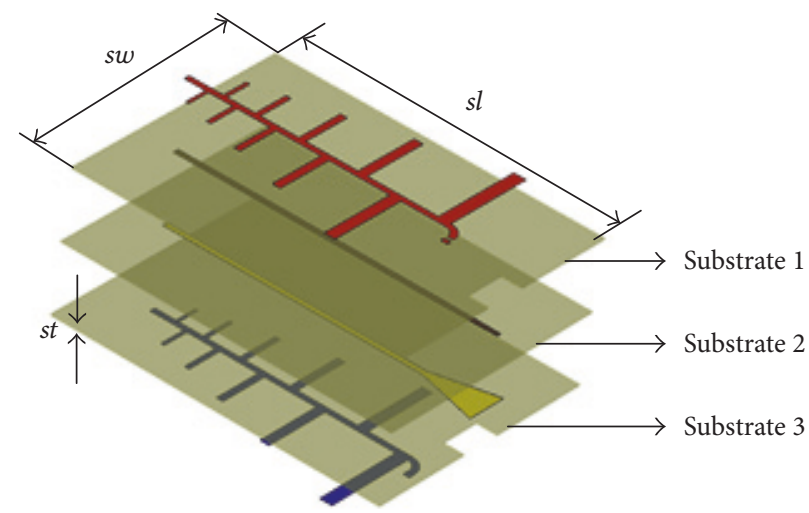

(b)

FIGURE 1: Prototype of the printed LPDA antenna and design parameters. (a) Layout. (b) Integrations. 


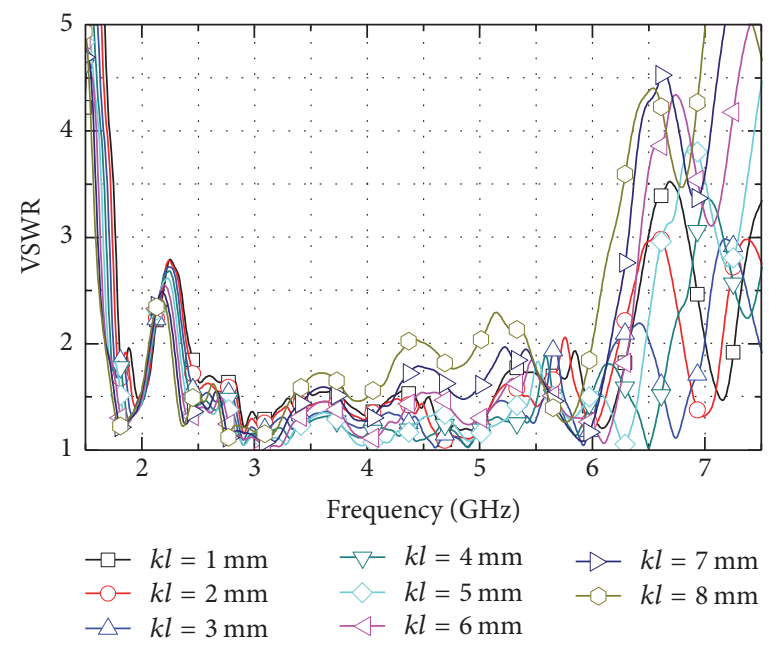

FIGURE 2: Simulated VSWR of various values of $k l$.
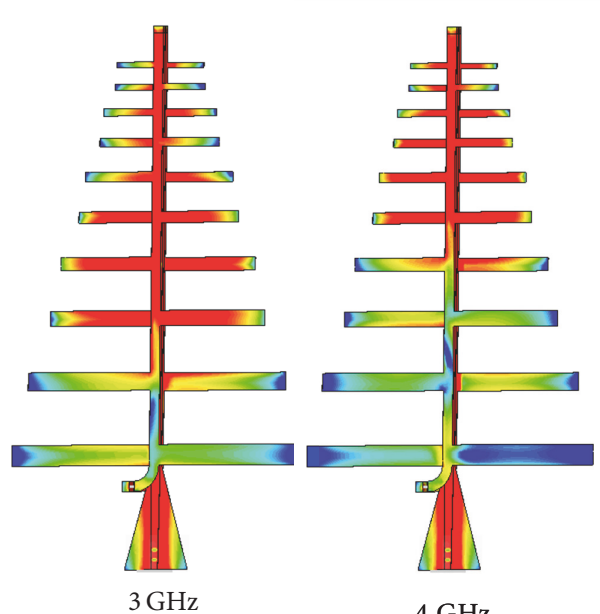

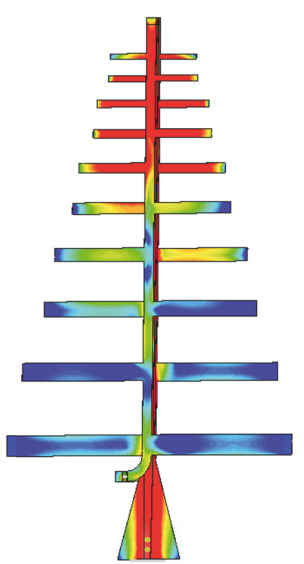

$5 \mathrm{GHz}$

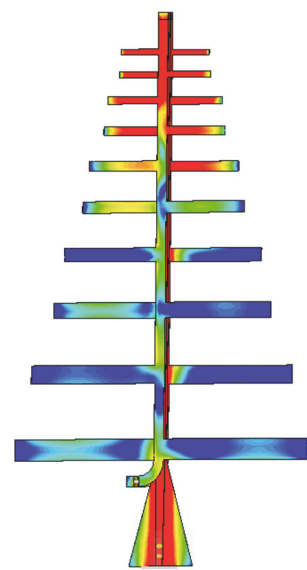

$6 \mathrm{GHz}$

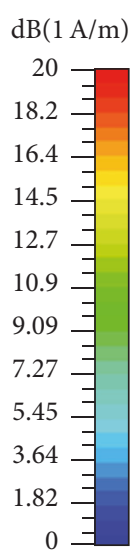

FIGURE 3: Current density of the printed LPDA antenna.

TABLE 2: Dimensions of the printed LPDA antenna.

\begin{tabular}{lc}
\hline Parameters & Value $(\mathrm{mm})$ \\
\hline$k l$ & 6 \\
$w k$ & 1.5 \\
$w t$ & 1.2 \\
$w b$ & 10 \\
$h$ & 15 \\
$r$ & 4.25 \\
$s w$ & 60 \\
$s l$ & 80 \\
\hline
\end{tabular}

of current density when the antenna works at varied frequencies. From the amplitude of the current density in this figure, we can see that the active region in the proposed antenna moves to the shorter dipoles with the frequency becoming larger. From the vertex to the active region and from the active region to the end of the antenna, the amplitude of the current density is very small and its radiation effects can be ignored.
To experimentally validate the presented concept, theantenna described above is fabricated and shown in Figure 4. All the parameters in the fabricated antenna are obtained by the simulation. The measured contents include VSWR, gain, and radiation pattern. The simulated and measured frequency responses of VSWR are shown in Figure 5, which clearly show that a bandwidth $(2.5-6 \mathrm{GHz})$ within VSWR $<2$ is achieved. It is found that the input impedance changes a little with the frequency changes.

Simulated and measured realized gain are shown in Figure 6. It is clear that, for much of the frequency range, the peak gain is quite stable and greater than $6 \mathrm{dBi}$. Simulated and measured radiation patterns of the antenna are shown in Figure 7. Referring to the orientation of the fabricated antenna in Figure 4, the E-plane in Figure 7 is the $y z$-plane in Figure 4 and the $H$-plane in Figure 7 is $x z$-plane in Figure 4. With the frequency changes, the radiation patterns remain relatively unchanged. According to the simulation results, the cross-polarization is not shown since it is always below $-30 \mathrm{~dB}$ with respect to the copolarization. The measured 


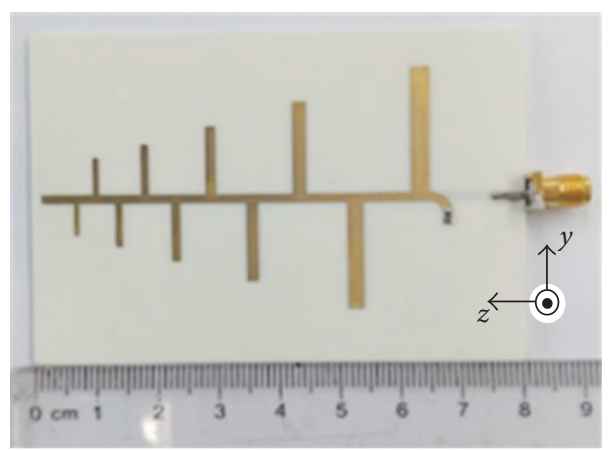

(a)

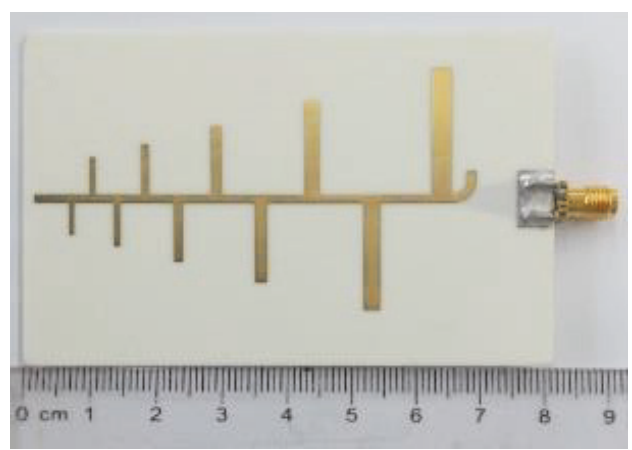

(b)

FIgURE 4: Photograph of the fabricated printed LPDA antenna. (a) Top view. (b) Bottom view.

TABLE 3: Comparison with other related work.

\begin{tabular}{lccccccc}
\hline Ref. & VSWR & $\begin{array}{c}\text { Radiation } \\
\text { pattern }\end{array}$ & Feeding position & $\begin{array}{c}\text { Feeding } \\
\text { transmission } \\
\text { line }\end{array}$ & Bandwidth & Average gain & $\begin{array}{c}\text { Cross- } \\
\text { polarization }\end{array}$ \\
\hline Reference [5] & $<2$ & Good & Backside & Coaxial line & $0.35-0.75 \mathrm{GHz}$ & $7 \mathrm{~dB}$ & Not mentioned \\
Reference [6] & $<2$ & Good & Backside & Coaxial line & $2.4-3 \mathrm{GHz}$, & $5.2-5.8 \mathrm{GHz}$ & \\
Reference [7] & $<2.5$ & Good & Head & MSL & $1-4 \mathrm{GHz}$ & Not mentioned & Not mentioned \\
Reference [8] & $<2$ & Good & Head & DSPSL & $1.1-13.8 \mathrm{GHz}$ & $5.2 \mathrm{~dB}$ & $-20 \mathrm{~dB}$ \\
Reference [9] & $<2.5$ & Good & Backside & Strip line & $4-8 \mathrm{GHz}$ & $9 \mathrm{~dB}$ & Not mentioned \\
Reference [11] & $<2$ & Good & Backside & Coplanar & $3-6 \mathrm{GHz}$ & $6.85 \mathrm{~dB}$ & $-25 \mathrm{~dB}$ \\
Reference [13] & $<2$ & Good & Backside & DSPSL & $4.2-9.2 \mathrm{GHz}$ & $7 \mathrm{~dB}$ & $-30 \mathrm{~dB}$ \\
This work & $<2$ & Good & Backside & MSL & $2.5-6 \mathrm{GHz}$ & $6.5 \mathrm{~dB}$ & $-30 \mathrm{~dB}$ \\
\hline
\end{tabular}

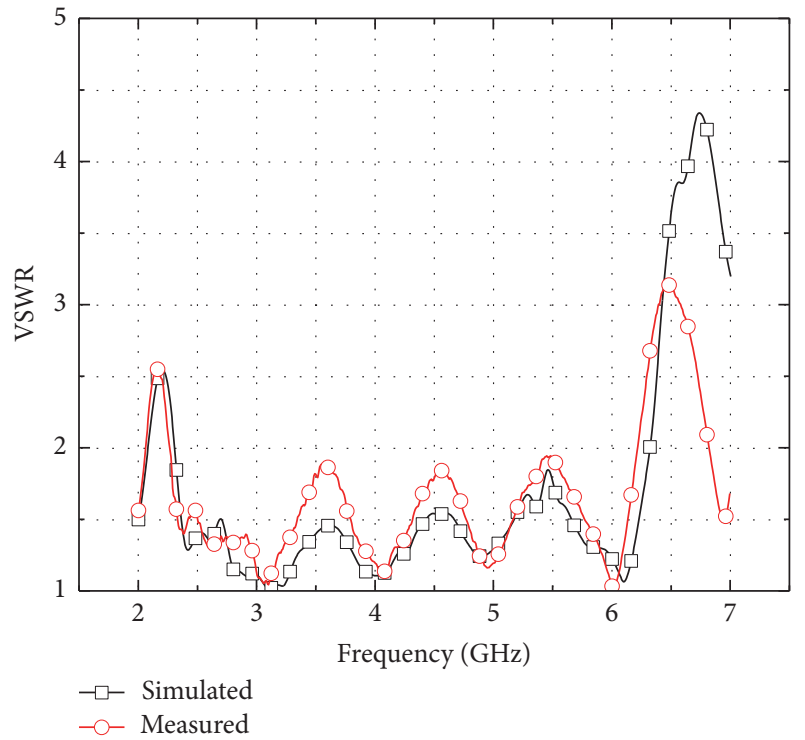

FIGURE 5: Simulated and measured VSWR of the printed LPDA antenna.

VSWR, realized gain, and radiation patterns are in very good agreement with the simulations. From the results, we can see that there is little difference between this printed LPDA

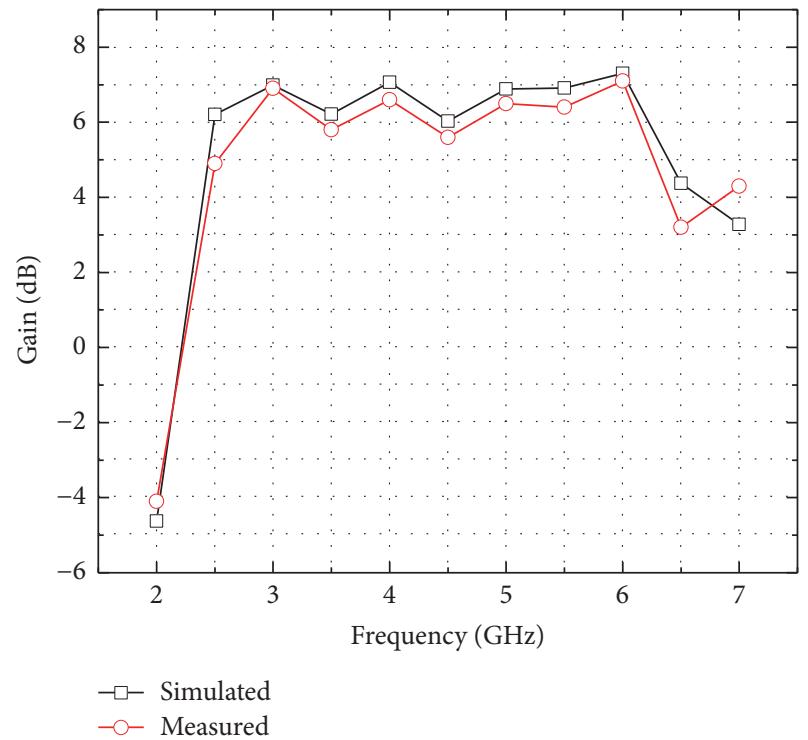

FIGURE 6: Simulated and measured realized gain of the printed LPDA antenna.

antenna and the traditional LPDA antenna, but the feeding technique in this paper is more compact. Some of the recently reported antennas are listed in Table 3. It is noticed from 


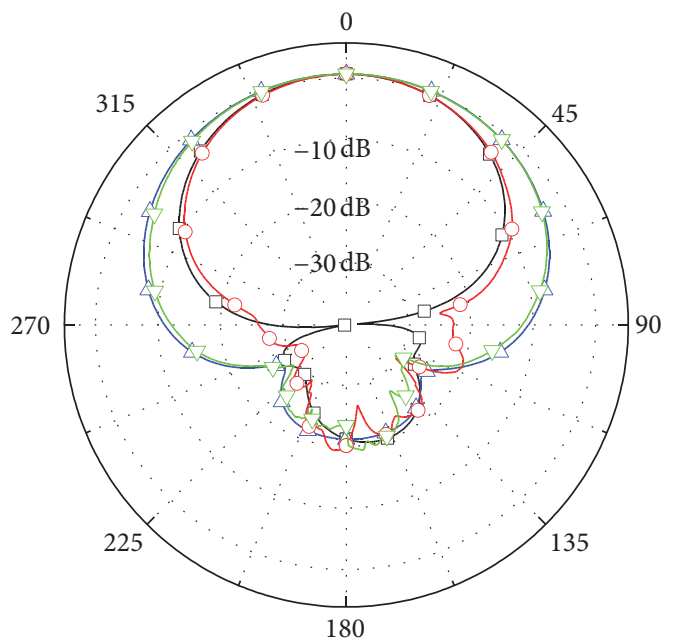

(a)

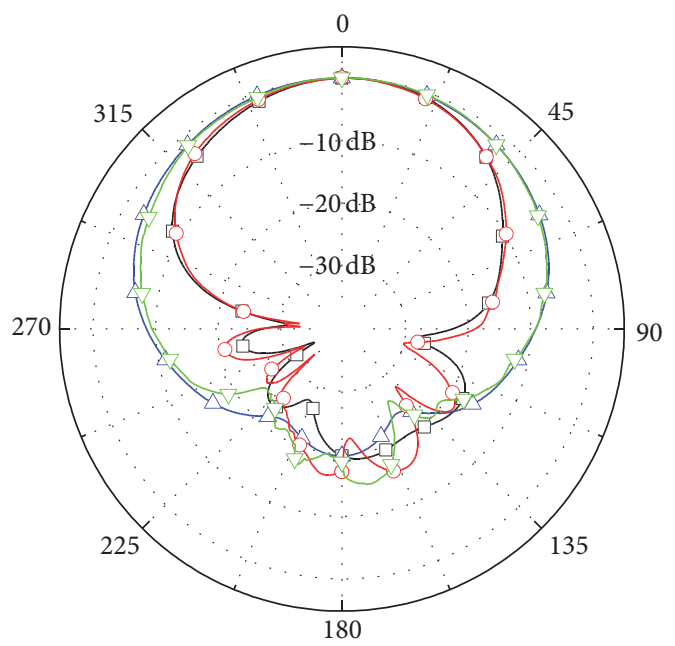

(c)

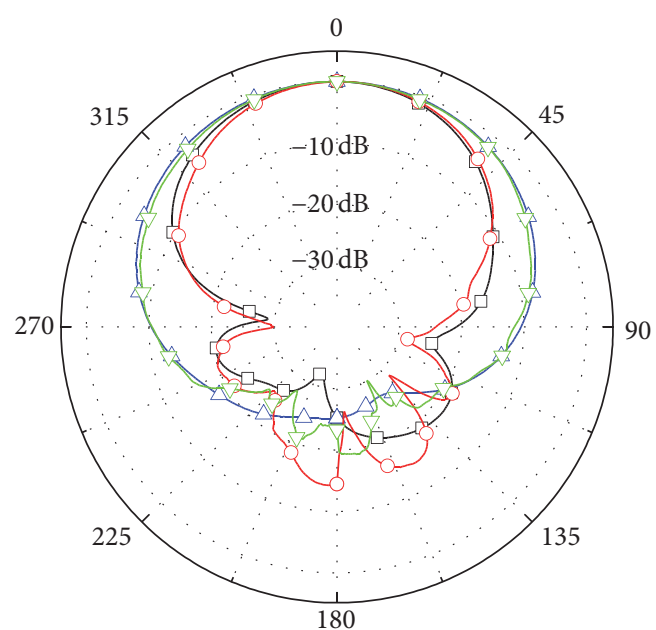

(b)

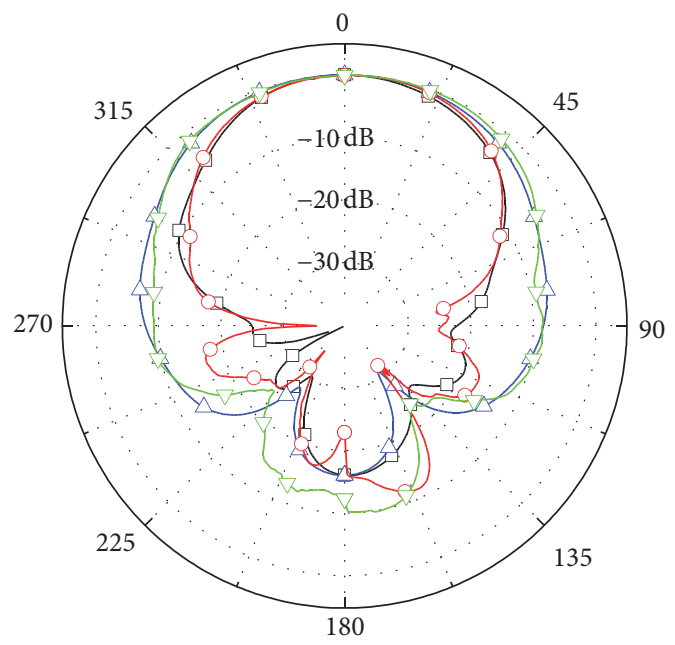

(d)

$\square-$ E-plane (simulated)
$-\quad H$-plane (simulated)
$-\circ$ - E-plane (measured)
$\neg-H$-plane (measured)

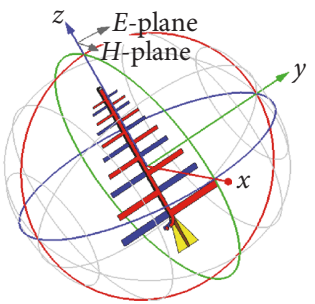

Figure 7: Simulated and measured radiation pattern of the printed LPDA antenna. (a) $f=3 \mathrm{GHz}$. (b) $f=4 \mathrm{GHz}$. (c) $f=5 \mathrm{GHz}$. (d) $f=6 \mathrm{GHz}$.

the comparison in this table that this paper provides a novel feeding technique for the printed LPDA antenna.

\section{Conclusion}

A printed LPDA antenna with a novel feeding technique is proposed in this paper. Comparison between simulated and measured results has proven the suitability of this approach. The antenna showed a good result over 2.5 to $6 \mathrm{GHz}$ frequency range with $2: 1 \mathrm{VSWR}$, an average gain of
$6.5 \mathrm{~dB}$, and stable radiation patterns. The use of a tapered MSL balun allows a simple realization, is of low cost and compact size, and is easy to connect with the external SMA connectors or other RF circuits.

\section{Conflicts of Interest}

The authors declare that there are no conflicts of interest regarding the publication of this paper. 


\section{References}

[1] R. DuHamel and D. Isbell, "Broadband logarithmically periodic antenna structures," in Proceedings of the IRE International Convention Record, pp. 119-128, New York, NY, USA.

[2] R. Carrel, "The design of log-periodic dipole antennas," in Proceedings of the IRE International Convention Record, vol. 9, pp. 61-75, New York, NY, USA, March 1961.

[3] C. H. Ahn and K. Chang, "Wideband coplanar stripline to double-sided parallel-strip line transition," Electronics Letters, vol. 45, no. 14, pp. 748-749, 2009.

[4] R.-P. Zheng, Z. Shi, C.-J. Guo, and J. Ding, "A wideband printed quadruple-element antenna with integrated balun," IEEE Antennas and Wireless Propagation Letters, vol. 12, pp. 959-963, 2013.

[5] N. A. Bishop, J. Miller, D. Zeppettella, W. Baron, J. Tuss, and M. Ali, "A Broadband High-Gain Bi-Layer LPDA for UHF Conformal Load-Bearing Antenna Structures (CLASs) Applications," IEEE Transactions on Antennas and Propagation, vol. 63, no. 5, pp. 2359-2364, 2015.

[6] G. A. Casula and P. Maxia, "A multiband printed log-periodic dipole array for wireless communications," International Journal of Antennas and Propagation, vol. 2014, Article ID 646394, 6 pages, 2014.

[7] M. I. Mirzapour, S. M. J. Razavi, and S. H. M. Armaki, "Ultrawideband planar LPDA antenna with mode converter balun," Electronics Letters, vol. 50, no. 12, pp. 848-850, 2014.

[8] G. Bozdag and A. Kustepeli, "Subsectional Tapered Fed Printed LPDA Antenna with a Feeding Point Patch," IEEE Antennas and Wireless Propagation Letters, vol. 15, pp. 437-440, 2016.

[9] R. R. Pantoja, A. R. Sapienza, and F. C. Medeiros Filho, "A Microwave Printed Planar Log-Periodic Dipole Array Antenna," IEEE Transactions on Antennas and Propagation, vol. 35, no. 10, pp. 1176-1178, 1987.

[10] A. Khaleghi, H. S. Farahani, and I. Balasingham, "Impulse radiating log-periodic dipole array antenna using time-reversal technique," IEEE Antennas and Wireless Propagation Letters, vol. 10, pp. 967-970, 2011.

[11] G. A. Casula, P. Maxia, G. Montisci, G. Mazzarella, and F. Gaudiomonte, "A printed LPDA Fed by a coplanar waveguide for broadband applications," IEEE Antennas and Wireless Propagation Letters, vol. 12, pp. 1232-1235, 2013.

[12] G. A. Casula, G. Montisci, P. Maxia, G. Valente, A. Fanti, and G. Mazzarella, "A Low-Cost Dual-Band CPW-Fed Printed LPDA for Wireless Communications," IEEE Antennas and Wireless Propagation Letters, vol. 15, pp. 1333-1336, 2016.

[13] C.-Y. Kang, S. Lin, Z.-H. Zhao, and L.-W. Jing, "The simulation and experiment of a non-cross-feeding printed log-periodic antenna," International Journal of Antennas and Propagation, vol. 2015, Article ID 783405, 5 pages, 2015.

[14] M. Kobayashi and N. Sawada, "Analysis and Synthesis of Tapered Microstrip Transmission Lines," IEEE Transactions on Microwave Theory and Techniques, vol. 40, no. 8, pp. 1642-1646, 1992.

[15] P. L. Carro and J. De Mingo, "Analysis and synthesis of double-sided parallel-strip transitions," IEEE Transactions on Microwave Theory and Techniques, vol. 58, no. 2, pp. 372-380, 2010.

[16] C. A. Balanis, Antenna Theory: Analysis and Design, John Wiley \& Sons, New York, NY, USA, 2012. 


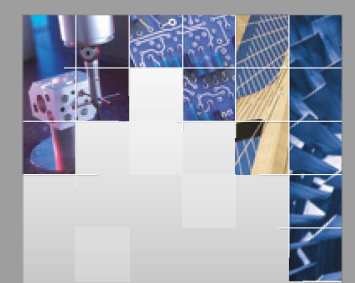

\section{Enfincering}
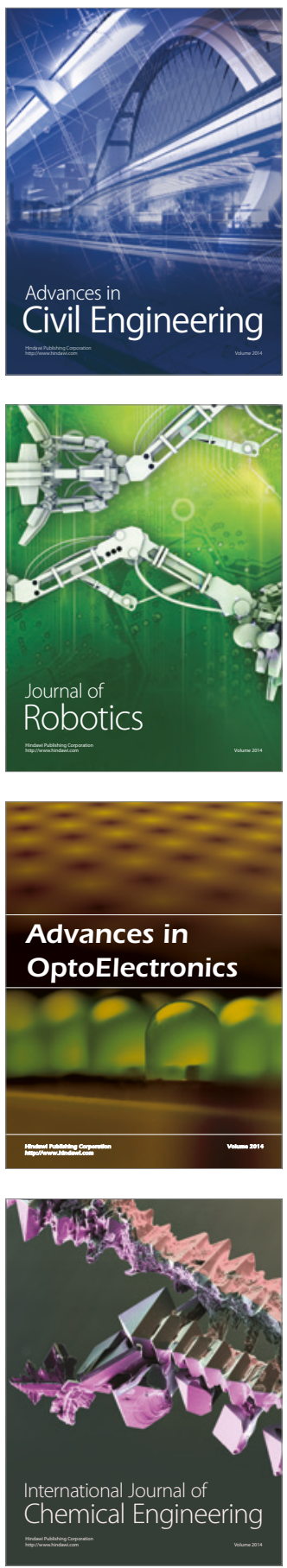

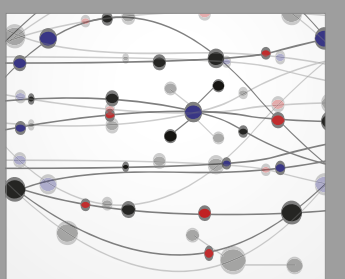

The Scientific World Journal

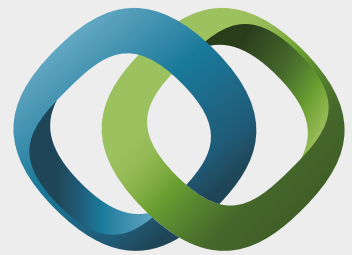

\section{Hindawi}

Submit your manuscripts at

https://www.hindawi.com
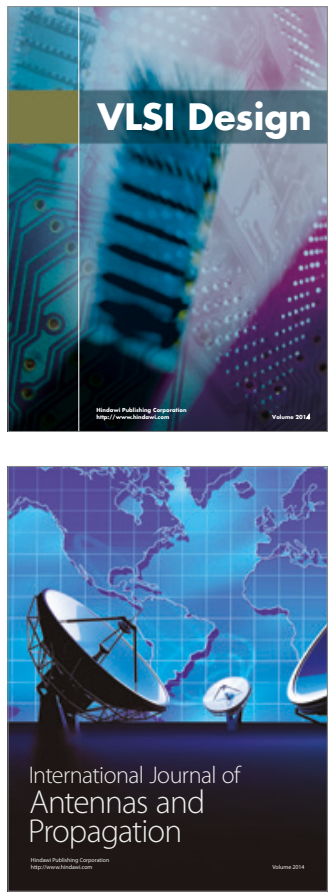

\section{Rotating}

Machinery
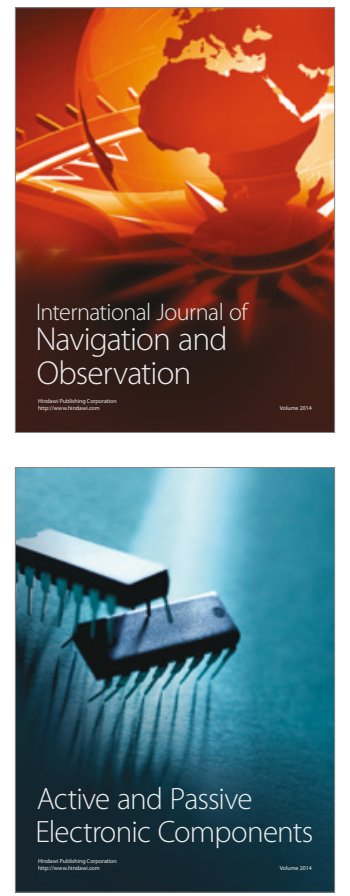
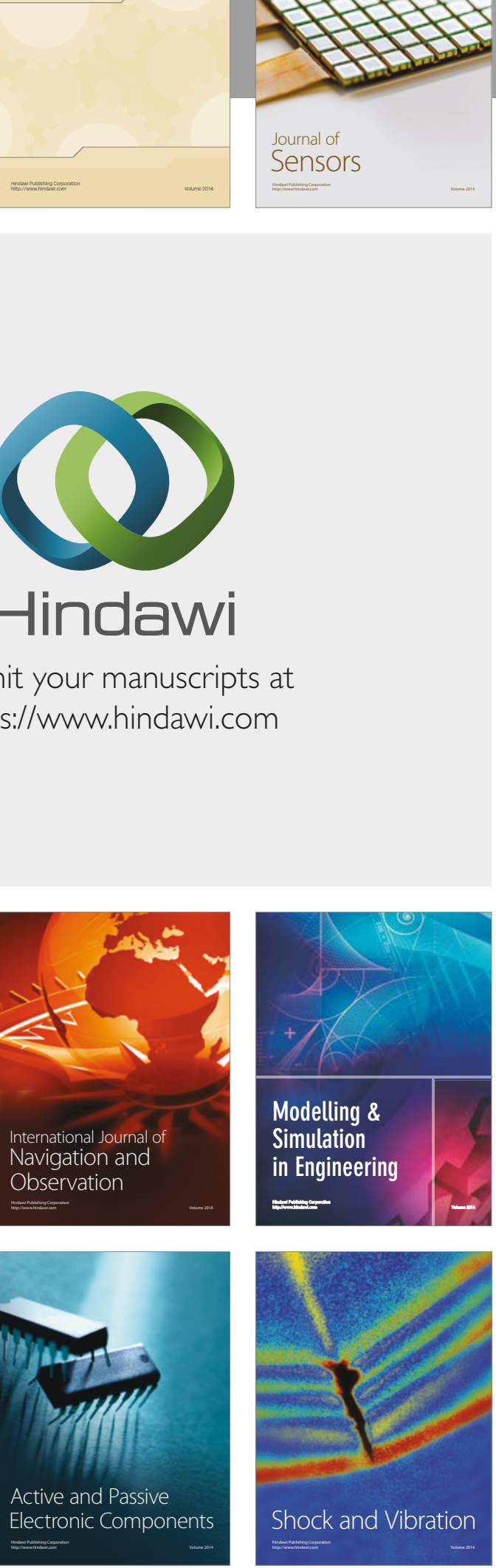
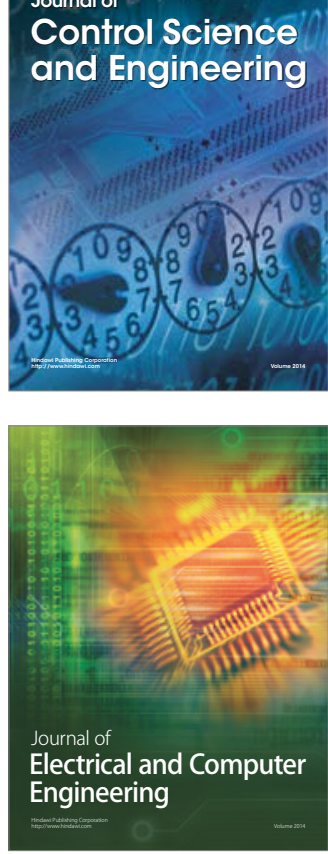

Distributed

Journal of

Control Science

and Engineering
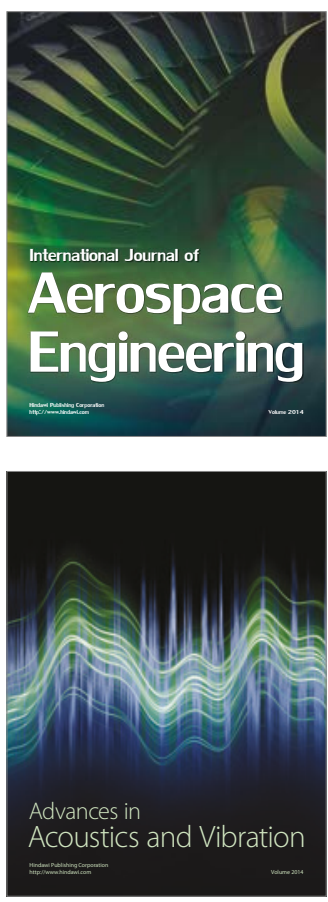

Sensor Networks 